\title{
Endobronchial Valves for Persistent Postoperative Pulmonary Air Leak: Accurate Monitoring and Functional Implications
}

\author{
Christophe A. Dooms ${ }^{a}$ Paul R. De Leyn ${ }^{b}$ Jonas Yserbyt ${ }^{a} \quad$ Herbert Decaluwe $^{b}$ \\ Vincent Ninane ${ }^{a}$ \\ Departments of a Pulmonology and ${ }^{b}$ Thoracic Surgery, University Hospitals Leuven, Leuven, Belgium
}

\section{Established Facts}

- Digital drainage systems facilitate timely removal of chest tubes after pulmonary resection.

- Collateral ventilation is the bane of bronchoscopic lung volume reduction using endobronchial valves.

\section{Novel Insights}

- Digital drainage systems facilitate decision making during endobronchial valve placement for pulmonary air leak.

- Collateral ventilation may be an advantage when endobronchial valves are used for air leak closure.

\section{Key Words}

Air leak · Bronchoscopy · Digital • Endobronchial valve • Lung surgery

\begin{abstract}
An alveolar-pleural fistula is a communication between the pulmonary parenchyma distal to a segmental bronchus and the pleural space. A postoperative pulmonary expiratory air leak after an anatomic pulmonary resection is usually managed conservatively. The use of endobronchial valves is a minimal invasive method that may be effective for the treatment of a persistent postoperative pulmonary air leak. We present and discuss the advantages of a digital thoracic drainage system for the accurate, objective and reproduc-
\end{abstract}

\section{KARGER}

Fax +4161306 1234

E-Mail karger@karger.ch

www.karger.com (c) 2012 S. Karger AG, Basel

$0025-7931 / 12 / 0844-0329 \$ 38.00 / 0$

Accessible online at:

www.karger.com/res ible air leak assessment during endobronchial valve placement. Our case also illustrates that, even after lobectomy, lobar exclusion with valves allows air leak resolution without atelectasis and with moderate functional alteration. We discuss the anatomic and physiologic changes induced by valves placed for air leak closure.

Copyright @ 2012 S. Karger AG, Basel

\section{Introduction}

A postoperative pulmonary air leak after an anatomic pulmonary resection is usually managed conservatively such as with a longer period of drainage or use of a Heimlich valve. Using a traditional chest drainage system the 
Fig. 1. Quantitative measurement of the air leak $\left(\mathrm{ml} / \mathrm{min}^{-1}\right)$ using a digital thoracic drainage system (Thopaz ${ }^{\mathrm{TM}}$ ) during the placement (h) of the EBV showing a gradual decrease of the airflow. A residual airflow of $100 \mathrm{ml} / \mathrm{min}^{-1}$ was obtained at the end of the intervention.

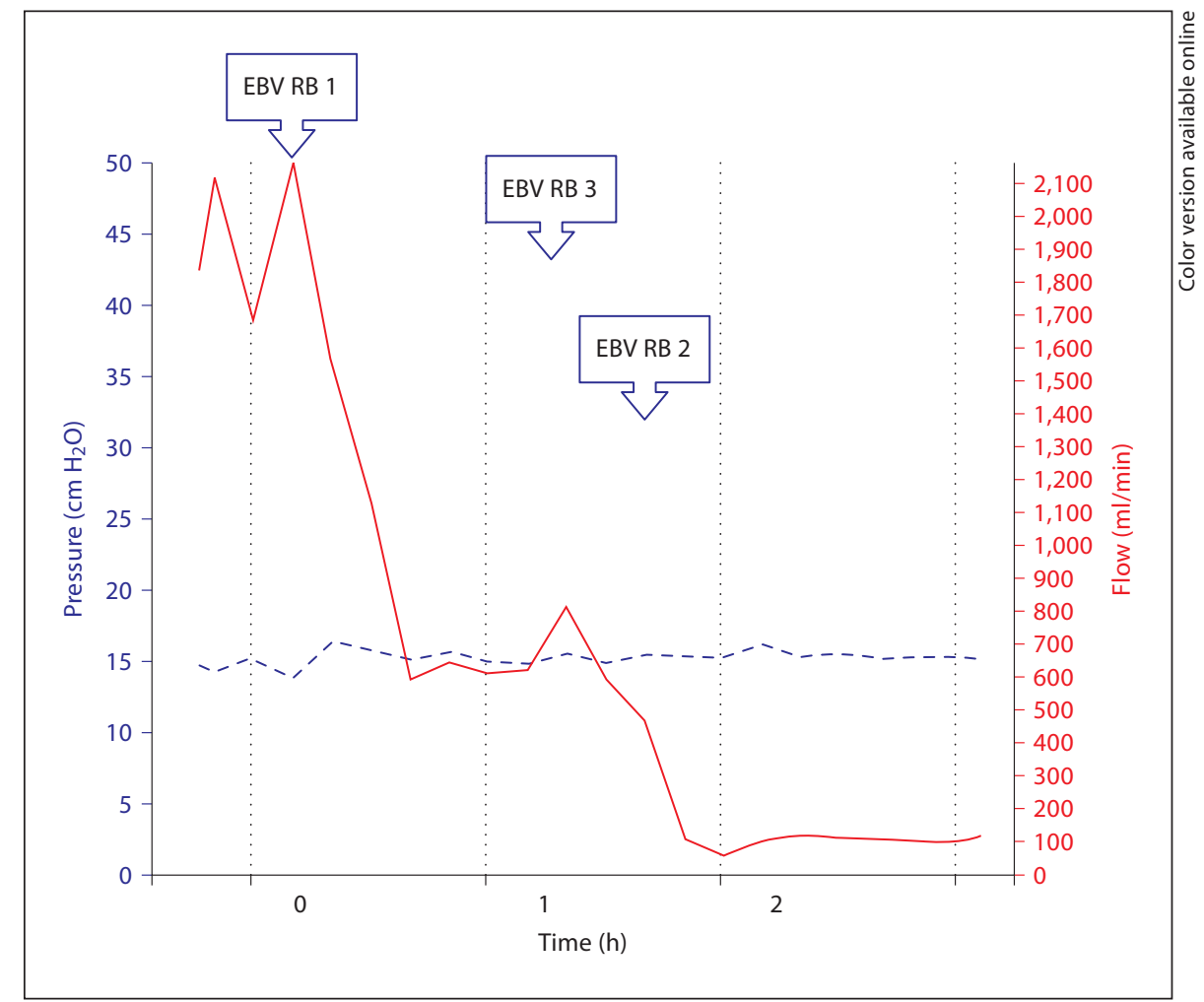

assessment of an air leak relies on a subjective and instantaneous assessment of expiratory bubble formation in the water seal column during spontaneous or forced expiratory breathing. The main shortcomings of this method are its dependence on subjective interpretation of the course of bubbles and the impossibility of recording the test results, making this assessment suboptimal for accurate air leak assessment or early timing of chest drain removal.

The use of endobronchial valves (EBV) is a minimal invasive method that may be effective for the treatment of persistent postoperative pulmonary air leak in patients [1-4]. Case series provided this scientific guidance based on a subjective assessment of air leak reduction $[2,3]$. The mean time from valve placement to chest tube removal was 19-21 days (median 8-16 days) in case series using a traditional chest drainage system [2,3]. A clear-cut quantification of the air-loss from the lung surface may help to establish an algorithm for the management of postoperative alveolar-pleural fistulae using EBV. A digital thoracic drainage system is able to continuously monitor and record the amount of air leak, providing an objective and reproducible air leak assessment which is a critical factor in appropriate endobronchial valve placement.
We present herein the clinical application of an objective and reproducible air leak measurement system through which successful endobronchial valve placement resulting in early air leak cessation and chest drain removal is appropriate.

\section{Case Report}

A 72-year-old male with moderate centrilobular emphysema underwent a right-sided video-assisted thoracoscopic right lower lobectomy for a pT1aN0M0 squamous cell lung cancer. His postoperative course was complicated with a persistent postoperative prolonged air leak. The chest tube was connected to a digital thoracic drainage system (Thopaz ${ }^{\mathrm{TM}}$, Medela AG, Switzerland) measuring at postoperative day 7 an air leak of 1,800-2,200 $\mathrm{ml}$ per $\min \left(\mathrm{ml} / \mathrm{min}^{-1}\right)$.

During flexible bronchoscopy under spontaneous ventilation we were able to demonstrate that the air leak almost stopped while occluding the right upper lobe (RUL) whereas no change was observed during middle lobe occlusion. The patient gave his signed consent for endobronchial valve placement. The procedure was approved by our Institutonal Review Board (B32220096119). The patient was scheduled at postoperative day 10 for the placement of EBV (Spiration Inc.) designed to control an air leak that persisted after lung surgery. Valve implantation in the right bronchi (RB 1-3) of the RUL ('lobar exclusion') was decided because balloon occlu- 
sion of each isolated segment or any combination of two segments could not stop the leak. A first EBV placed in RB 1 resulted in a drop of the air leak to $800 \mathrm{ml} / \mathrm{min}^{-1}$ (fig. 1). A second and third EBV placed in RB 3 diminished the flow to $500-600 \mathrm{ml} / \mathrm{min}^{-1}$ (fig. 1). Finally, $1 \mathrm{EBV}$ was introduced in $\mathrm{RB} 2$ resulting in a residual airflow of $100 \mathrm{ml} / \mathrm{min}^{-1}$ (fig. 1). The endoscopic view at the end of the procedure shows $4 \mathrm{EBV}$ in the right upper lobe (fig. 2). The day after EBV placement a chest x-ray demonstrated no pneumothorax or RUL atelectasis. The continuous digital air leak assessment demonstrated that the airflow remained stable between 100 and $200 \mathrm{ml} / \mathrm{min}^{-1}$ and suddenly stopped at $36 \mathrm{~h}$ after valve insertion (fig. 3). The chest drain could be successfully removed within $72 \mathrm{~h}$.

The 4 EBV were electively removed 3 weeks after their insertion. Removal had a beneficial impact on the patients' dyspnea. The VAS dyspnea score improved from 7 after valve placement to 3 after valve removal. A pulmonary function test before and 1 day after valve removal showed no change in TLC but an increase in $\mathrm{FEV}_{1}$ of $400 \mathrm{ml}$ and a decrease in $\mathrm{RV}$ of $500 \mathrm{ml}$ (table 1).

\section{Discussion}

A persistent postoperative pulmonary air leak might account for postoperative morbidity after lung surgery. Air leak assessment using a traditional chest drainage system relies on a subjective and instantaneous assessment of expiratory bubble formation in the water seal column, making this assessment suboptimal for accurate air leak assessment during valve placement $[2,3]$. A digital thoracic drainage system is able to continuously monitor and record the air leak in milliliter leakage per minute $(\mathrm{ml} /$ $\mathrm{min}^{-1}$ ) providing an objective and reproducible quantitative air leak assessment, which seems helpful in appropriate valve placement and timing of chest drain removal.

The anatomic and physiologic changes induced by EBV placement for air leak closure also deserved our attention in particular because lobar exclusion after previous lobectomy may cause respiratory failure. Absence of atelectasis after lobar exclusion for persistent air leak in our case was highly suggested by chest $\mathrm{x}$-ray and the unchanged TLC (table 1), and is indicative of collateral ventilation. In emphysematous patients incomplete fissures are probably very frequent [5]. Our patient had nearly normal lung parenchyma and it seems then likely that resistance to airflow through collateral channels is higher than in an emphysematous lung [6]. However, this presumably high collateral resistance does not seem to be high enough to completely impede collateral airflow with absence of atelectasis and residual air leak as consequences. At the same time, collateral resistance in the present case does not seem to be low enough to allow significant residual air leak that could prevent quick leak closure.

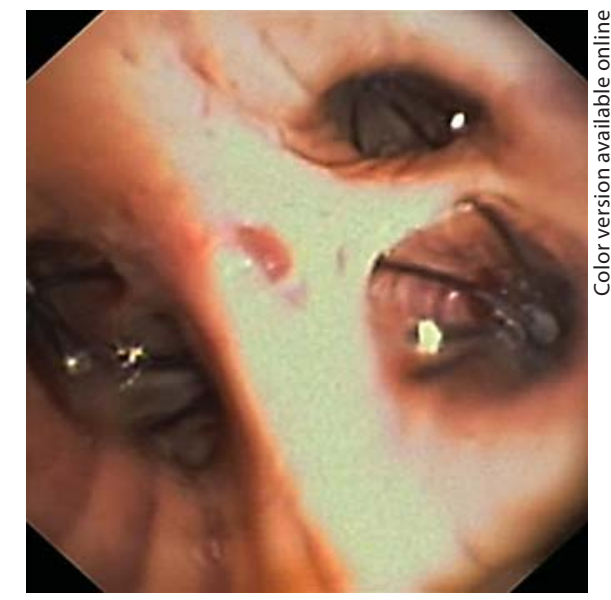

Fig. 2. Endoscopic view of the EBV after placement in the RUL.

Table 1. Preoperative and postoperative pulmonary function tests before and after EBV removal

\begin{tabular}{lcll}
\hline & Preoperative & $\begin{array}{l}\text { Day before } \\
\text { EBV removal }\end{array}$ & $\begin{array}{l}\text { Day after } \\
\text { EBV removal }\end{array}$ \\
\hline $\mathrm{FEV}_{1}$, liters & $2.77(79)$ & $1.98(56)$ & $2.37(67)$ \\
$\mathrm{FVC}_{\text {liters }}$ & $4.07(88)$ & $3.41(74)$ & $3.82(83)$ \\
$\mathrm{FEV}_{1} / \mathrm{FVC}, \%$ & 68 & 58 & 62 \\
$\mathrm{TLC}_{\text {, liters }}$ & $8.07(102)$ & $6.98(89)$ & $6.96(89$ \\
$\mathrm{RV}$, liters & $3.92(139)$ & $3.58(130)$ & $3.09(112)$ \\
\hline
\end{tabular}

Figures in parentheses indicate percent predicted.

Absence of atelectasis after lobar exclusion for persistent air leak thus depends on the presence of incomplete fissures. Indeed, the preoperative CT scan of the chest revealed an incomplete fissure at the hilum between RUL and RML (fig. 4). The functional evaluation reveals that $\mathrm{FEV}_{1}$ was clearly reduced in our patient, most likely due to RUL airway obstruction and air trapping at end expiration with increased $\mathrm{RV}$, both associated with increased dyspnea (table 1). These findings differ from the results observed in bronchoscopic lung volume reduction trials where the $\mathrm{FEV}_{1}$ is not decreased even when atelectasis is not present [7]. It must be stressed, however, that in these studies obstruction was performed in lobes with predominant emphysema, whereas in our case no major emphysema was observed in the RUL. In addition, one may also hypothesize that lung volume reduction was already obtained in our case by the previous surgical right lower 
Fig. 3. Quantitative measurement of air leak $\left(\mathrm{ml} / \mathrm{min}^{-1}\right)$ using a digital thoracic drainage system (Thopaz) during the follow-up (h) after the placement of the EBV indicating the timing of the air leak closure.

Fig. 4. Pre-VATS CT scan of the chest. The minor fissure between RUL and RML is incomplete at the hilum. Sagittal plane (a) and coronal plane (b); full arrow indicates the minor fissure and dotted arrow indicates the incomplete part of the fissure.
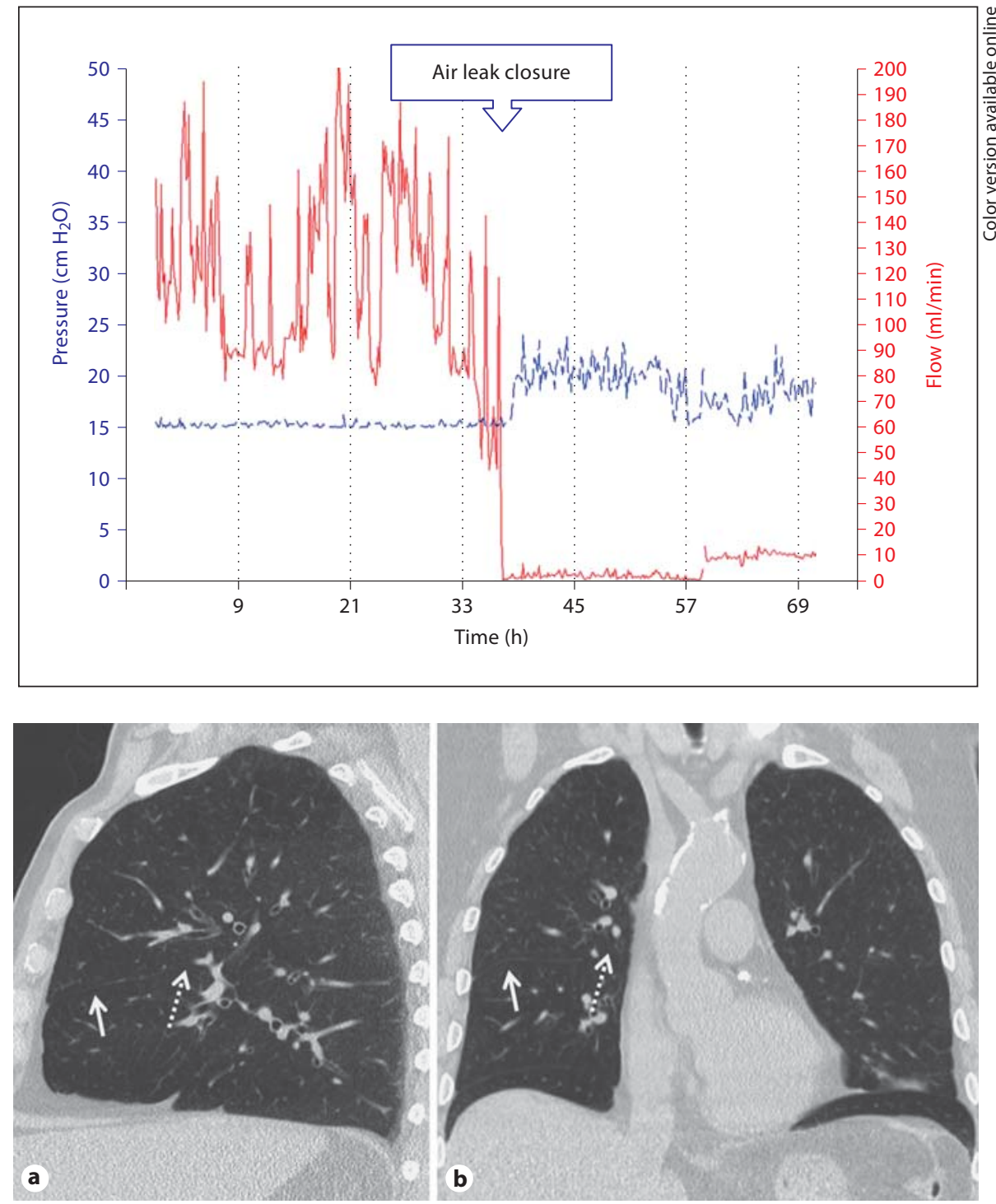

lobectomy. The presently decreased $\mathrm{FEV}_{1}$ and increased dyspnea suggest that respiratory failure may be a potential side effect of air leak treatment with EBV, in particular when this leak complicates lobectomy. However, this drawback seems limited because valve treatment is an easily reversible procedure, offering a quick answer in case of significant post-treatment complications [8].

In conclusion, the application of a digital thoracic drainage assessment of the air leak might guide endobronchial valve placement and allow a safe fast-tracking of chest tube removal. Air leak closure can be obtained with lobar occlusion without atelectasis at the cost of increased dyspnea and decreased $\mathrm{FEV}_{1}$ for a limited duration, until valve removal.

\section{Acknowledgements}

The authors are grateful to Olympus Belgium and Medela Benelux for supporting this investigation by donating the endobronchial valves (IBV ${ }^{\mathrm{TM}}$ valve system) and digital thoracic drainage system (Thopaz), respectively.

\section{Financial Disclosure and Conflicts of Interest}

None. 


\section{References}

$>1$ Toma T, Kon O, Oldfield W, et al: Reduction of persistent air leak with endoscopic valve implants. Thorax 2007;62:830-833.

$>2$ Travaline J, McKenna R, de Giacomo T, et al: Treatment of persistent air leaks using endobronchial valves. Chest 2009;136:355-360.

-3 Gillespie CT, Sterman DH, Cerfolio RJ, et al: Endobronchial valve treatment for prolonged air leaks of the lung: a case series. Ann Thorac Surg 2011;91:270-273.
4 US Food and Drug Administration: FDA approves lung valve to control some air leaks after surgery. 2008. www.fda.gov/NewsEvents/Newsroom/PressAnnouncements/ 2008/ucm116970.htm (accessed November 06, 2011).

$\checkmark 5$ Hopkinson NS, Toma TP, Hansell DM, et al: Effect of bronchoscopic lung volume reduction on dynamic hyperinflation and exercise in emphysema. Am J Respir Crit Care Med 2005; 171:453-460.
6 Terry P, Traystman R, Newball H, et al: Collateral ventilation in man. New Engl J Med 1978;298:10-15.

7 Sciurba F, Ernst A, Herth F, et al: A randomized study of endobronchial valves for advanced emphysema. N Engl J Med 2010;363: 1233-1244.

8 Sterman D, Mehta A, Wood DE, et al: A multicenter pilot study of a bronchial valve for the treatment of severe emphysema. Respiration 2010;79:222-233. 